\title{
INTEGRASI INTELLECTUAL CAPITAL DAN KNOWLEDGE MANAGEMENT SERTA DAMPAKNYA TERHADAP PENINGKATAN KINERJA PENJUALAN UKM KOTA TANGERANG
}

\author{
Humairoh $^{1}$ dan Agung Budi ${ }^{2}$ \\ ${ }^{1,2}$ Dosen Fakultas Ekonomi dan Bisnis Universitas Muhammadiyah Tangerang \\ Maira_mamay@umt.ac.id \\ agungbudi@umt.ac.id
}

\begin{abstract}
Abstrak
Tujuan penelitian ini menguji pengaruh intellectual capital dan knowledge management terhadap peningkatan kinerja penjualan UKM di Kota Tangerang, Propinsi Banten. Sampel berjumlah 98 pelaku usaha UKM Kota Tangerang sebagai responden. Pengambilan sampel dengan menggunakan teknik purposive sampling dengan menggunakan instrumen kuesioner dengan skala likert 1-5. Penelitian ini menggunakan teknik path analysis dengan program Smart PLS.
\end{abstract}

Hasil penelitian ini menunjukkan bahwa intellectual capital dan knowledge management berpengaruh positif dan signifikan terhadap peningkatan kinerja penjualan UKM. Peningkatan kinerja penjualan dapat dijelaskan oleh intellectual capital dan knowledge management sebesar 89,6\%.

\section{Kata Kunci : Kinerja Penjualan, Inovasi Produk, Intellectual Capital, Knowledge Management}

\begin{abstract}
The aims of this study are analyzing the influence of intellectual capital and knowledge management againts sales performace on $S M E_{S}$. The reseach type is a causal research to obtain evidences of causal relationships with a sample of 98 respondents as business owners SMES. The sampling technique used purposive sampling with questionnaires as the instrument to collect data whose result processed using method Scala Likert Summated Rating (LSR) with score 1 - 5. This research used technique of path analysis using Smart PLS.

The results of this hypothesis indicated that intellectual capital and knowledge management has a positive and significant influence on sales performance. The contribution of intellectual againt and knowledge management sales performace on SMEs by 89,6\%.
\end{abstract}

\section{Keywords: Sales Performance, Product Innovation, Intellectual Capital, Knowledge Management}

\section{PENDAHULUAN}

Era globalisasi ditandai dengan perkembangan ilmu pengetahuan dan teknologi yang sangan pesat. Pada saat ini, dunia bisnis tengah mengalami perubahan dalam ekonomi yang berbasis produksi (tradisional) menjadi ekonomi berbasis pengetahuan. Peningkatan daya saing Usaha Kecil Menengah (UKM) tergantung pada kearifan pengelolaan pengetahuan dan teknologi. Adapun ilmu pengetahuan dan teknologi diciptakan dari knowledge perorangan 
yang harus dikelola agar menjadi knowledge perusahaan, yang akhirnya knowledge menjadi aset perusahaan UKM. Knowledge merupakan pengalaman, informasi tekstual dan pendapat para pakar pada bidangnya. Oleh karena itu suatu perusahaan UKM akan berkelanjutan apabila menggunakan informasi atau pengalaman tersebut guna terciptanya kompetisi UKM

Melihat kondisi UKM di Indonesia sepertinya belum banyak yang menyadari pentingnya bisnis berbasis pengetahuan (knowledge) dengan mengoptimalkan modal intelektual (intellectual capital) yang dimilikinya, padahal keberadaan UKM sangat diharapkan eksitensinya dalam menumbuhkan perekonomian dan mempunyai daya saing yang tinggi. Hal ini dikarenakan, UKM merupakan salah satu sektor industri yang memberikan konstribusi terbesar dalam perekonomian suatu negara. Begitu pula adanya UKM di Indonesia, sebagai sektor yang mempunyai peranan penting dan mampu bertahan dalam krisis yang melanda perekonomian Indonesia.

Kementerian Koperasi dan UKM mencatat kontribusi sektor UKM meningkat dari $57,84 \%$ menjadi $60,34 \%$. Sektor UKM juga telah membantu penyerapan tenaga kerja di dalam negeri. Serapan tenaga kerja pada sektor UKM tumbuh dari 96,99\% menjadi 97,22\% dalam periode lima tahun terakhir (CNN Indonesia.com, 21-11-2016, diakses 21 Maret 2018). Jumlah UKM Kota Tangerang tahun 2016 tercatat ada 10 ribu unit, hingga triwulan pertama tahun 2017 tercatat ada 10.553 unit atau bertambah 553 unit pelaku UKM. Adapun sejumlah produk UKM Kota Tangerang telah menembus pasar internasional sehingga mendorong warga lainnya untuk berwirausaha. (Neraca.co.id, diakses, 21 Maret 2018). Dengan kemampuan yang dimiliki tersebut, UKM di Kota Tangerang memiliki potensi dan peluang yang sangat besar untuk dapat tumbuh dan berkembang.

Namun demikian dari berbagai studi yang telah dilakukan menemukan bahwa salah satu kendala yang serius dihadapi oleh UKM dalam bidang produksi adalah rendahnya kualitas SDM. Latar belakang pendidikan pengusaha pada umumnya masih rendah sehingga sulit memahami atau menguasai teknologi yang diperlukan dan sulit menerima/beradaptasi dengan proses pembaharuan akibat perkembangan iptek yang sangat cepet. Hanya sebagian kecil saja yang mengikuti pelatihan teknis dan manajemen, padahal keberlangsungan aktivitas/proses dalam UKM, diperlukan suatu pelatihan yang merupakan suatu keharusan. Dengan UKM mengoptimalkan modal intelektual dan knowledge management yang ada diharapkan UKM dapat menghadapi persainagn dan mampu berkembang setiiap waktu seiring berkembanganya ilmu pengetahuan dan teknologi.

Beberapa kajian empirik telah membuktikan bahwa Intellectual capital berpengaruh terhadap peningkatan kinerja UKM (Hudgins, 2014; Zuliyati \& Delima, 2017 dan Humairoh \& Agung, 2019). Knowledge management berpengaruh signifikan pada kinerja organisasi (Choi, et al., 2008; Indriastuti \& Arifah, 2012).

Perumusan masalah dalam penelitian ini apakah intellectual capital dan knowledge management mempengaruhi peningkatan kinerja penjualan?. Sesuai dengan latar belakang dan permasalahan yang dikemukakan, maka tujuan penelitian ini adalah mengetahui pengaruh intellectual capital dan knowledge management terhadap peningkatan kinerja penjualan.

\section{METODELOGI PENELITIAN}

\section{Pendekatan dan Jenis Penelitian}

Pendekatan yang digunakan dalam penelitian ini adalah penelitian kuantitatif, yaitu metode penelitian yang berlandaskan pada filsafat positivisme, digunakan untuk meneliti pada populasi atau sampel tertentu, pengumpulan data menggunakan instrumen penelitian, analisis data bersifat kuantitatif/statistik, dengan tujuan untuk menguji hipotesis yang telah ditetapkan (Sugiyono, 2014). Adapun Jenis penelitian yang digunakan adalah penelitian 
Kausal. Penelitian kausal merupakan sebuah metode untuk menemukan kebenaran yang juga merupakan sebuah pemikiran kritis (critical thinking) penelitian meliputi pemberian definisi dari redevinisi terhadap masalah, memformulasikan hipotesis, membuat kumpulan dan sekurang-kurangnya mengadakan pengujian yang hati-hati atas semua kesimpulan untuk menentukan apakah cocok dengan hipotesis

\section{Jenis dan Sumber Data}

Jenis data yang digunakan dalam penelitian ini adalah data primer. Data primer adalah data yang didapat peneliti dari sumber pertama baik individu atau perseorangan seperti hasil wawancara atau pengisian kuesioner yang biasa dilakukan oleh peneliti.. Untuk memperoleh data tersebut, peneliti menyebarkan kuesioner kepada pelaku usaha UKM yang berada wilayah Kota Tangerang, Propinsi Banten. Pernyataan-pernyataan dalam kuesioner dibuat dengan menggunakan skala likert semantic kisaran 1-5.

\section{Populasi dan Sampel}

Populasi dalam penelitian ini adalah pelaku usaha UKM. Teknik pengambilan sampel yang digunakan dalam penelitian ini adalah melalui pendekatan non probability sampling yaitu purposive sampling. Berdasarkan purposive sampling, peneliti memilih sampel purposive secara subjektif dan dalam pemilihan sampel digunakan pertimbangan tertentu yang disesuaikan dengan tujuan atau masalah penelitian yang dikembangkan (Ferdinand 2006). Syarat sampel pada penelitian ini adalah pelaku usaha UKM yang berada wilayah Kota Tangerang, Propinsi Banten Jumlah sampel yang diambil dalam penelitian ini menggunakan rumus lameshow hal ini dikarenakan jumlah populasi tidak diketahui.

Keterangan :

$$
n=\frac{Z \alpha / 2^{2} \cdot p(1-p)}{d^{2}}=\frac{1,96^{2} \cdot 0,5(1-0,5)}{(0,1)^{2}}=96,04 \approx 100
$$

$n \quad$ : Jumlah sampel

$Z \alpha / 2$ : Tingkat keyakinan yang dibutuhkan dalam penentuan sampel $95 \%$.

Pada penentuan ini $\mathrm{Z}$ pada $\alpha=0,5$ adalah 1,96

$p \quad:$ Maksimal estimasi $=0,5$

d : Alpha $(0,10)$ atau sampling error $=10 \%$

Dalam penelitian ini kuesioner disebar kepada 100 responden, yang dikembalikan sebanyak 98 kuesioner. Dengan demikian data yang digunakan dalam penelitian ini berjumlah 98 sampel.

\section{Definisis Operasional Variabel}

Tabel 1. Variabel dan Indikator Penelitian

\begin{tabular}{|c|c|c|}
\hline Variabel & Indikator & Sumber \\
\hline \multirow{3}{*}{ Intellectual Capital $\left(\xi_{1}\right)$} & Human Capital (IC1) & \multirow{3}{*}{$\begin{array}{l}\text { (Tom Stewart dalam Paul L. } \\
\text { Tobing, 2007) }\end{array}$} \\
\hline & Structural Capital (IC2) & \\
\hline & Customer Capital (IC3) & \\
\hline \multirow{3}{*}{$\begin{array}{l}\text { Knowledge } \\
\text { Management }\left(\xi_{2}\right)\end{array}$} & Knowledge Creation (KM1) & \multirow{3}{*}{$\begin{array}{l}\text { (Sveiby, 2001, Edvinsson \& } \\
\text { Malone, 1997) }\end{array}$} \\
\hline & Knowledge Sharing (KM2) & \\
\hline & Knowledge Implementation (KM3) & \\
\hline \multirow{3}{*}{ Kinerja Penjualan $\left(\eta_{1}\right)$} & Pertumbuhan Penjualan (KP1) & \multirow{3}{*}{$\begin{array}{l}\text { (Kim dan Choi, 1994; Lee dan } \\
\text { Miller, 1996; luo, 1999; Miles, et. } \\
\text { al., 2000; Hadjimanolis, 2000). }\end{array}$} \\
\hline & Petumbuhan Pendapatan (KP2) & \\
\hline & Pertumbuhan Tenaga kerja (KP3) & \\
\hline
\end{tabular}


Pertumbuhan Pangsa Pasar (KP4)

Operasional variabel adalah penentuan konstruk sehingga menjadi variabel yang dapat diukur. Operasionalisasi variabel diperlukan untuk menentukan jenis, indikator, serta skala dari variabel-variabel yang terkait dalam penelitian.

\section{Metode Analisis Data}

Structural Equation Modeling (SEM) Partial Least Square (PLS) digunakan untuk mengukur hubungan setiap indikator dengan konstruknya. Selain itu, dalam PLS dapat dilakukan uji Bootstrapping terhadap struktural model yang bersifat outer model dan inner model.

Langkah-langkah analisis dengan metode Partial Least Square (PLS) sebagai berikut:

1. Merancang Model Pengukuran (Outer Model)

Perancangan model ini digunakan untuk mengetahui validitas dan reliabilitas yang menghubungkan indikator dengan variabel latennya. Indikator dalam penelitian ini adalah formatik karena indikator variabel laten mempengaruhi indikatornya.

2. Merancang Model Struktural (Inner Model)

Perancangan model struktural hubungan antar variabel laten didasarkan pada rumusan masalah atau hipotesis penelitian.

3. Konstruksi Diagram Jalur Penelitian

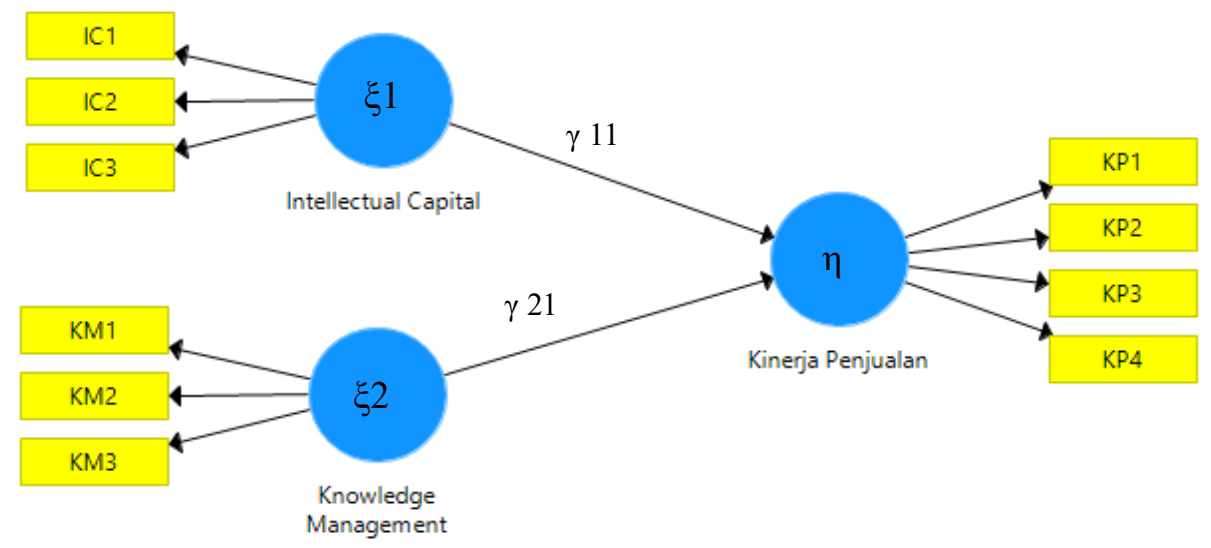

Gambar 2. Konstruksi Diagram Jalur Penelitian

4. Konversi Diagram Jalur ke Sistem Persamaan

1) Inner Model

Inner Model menentukan spesifikasi hubungan antara konstruk laten satu dengan kontrak laten lainnya.

Persamaan Inner Model:

$\eta=\gamma 11 \xi 1+\gamma 21 \xi 2+\zeta$

Keterangan:

$\xi 1=\quad$ Konstruk laten eksogen intellectual capital

$\xi 2=\quad$ Konstruk laten eksogen knowledge management

$\eta=$ Konstruk laten endogen kinerja penjualan

$\gamma 11=$ Koefisien intellectual capital terhadap kinerja penjualan

$\gamma 21=$ Koefisien knowledge management terhadap kinerja penjualan

2) Outer Model

Outer Model menentukan spesifikasi hubungan antara konstruk laten dan indikatornya. 
Persamaan Outer Model:

$\mathrm{IC} 1=\lambda \mathrm{IC} 1 \xi 2$

$\mathrm{IC} 2=\lambda \mathrm{IC} 2 \xi 2$

$\mathrm{IC} 3=\lambda \mathrm{IC} 3 \xi 2$

$\mathrm{KM} 1=\lambda \mathrm{KM} 1 \xi 1$

$\mathrm{KM} 2=\lambda \mathrm{KM} 2 \xi 1$

$\mathrm{KM} 3=\lambda \mathrm{KM} 3 \xi 1$

$\mathrm{KP} 1=\lambda \mathrm{KP} 1 \eta 2$

$\mathrm{KP} 2=\lambda \mathrm{KP} 2 \eta 2$

$\mathrm{KP} 3=\lambda \mathrm{KP} 3 \eta 2$

$\mathrm{KP} 4=\lambda \mathrm{KP} 4 \eta 2$

Keterangan:

$\lambda \mathrm{IC} 1-\lambda \mathrm{IC} 3=$ Koefisien indikator intellectual capital

$\lambda \mathrm{KM} 1-\lambda \mathrm{KM} 3=$ Koefisien indikator kowledge management

$\lambda \mathrm{KP} 1-\lambda \mathrm{KP} 4=$ Koefisien indikator kinerja penjualan

5. Evaluasi Goodness of Fit

Untuk memvalidasi model secara keseluruhan, maka digunakan goodness of fit (GoF). GoF index ini merupakan ukuran tunggal yang digunakan untuk memvalidasi performa gabungan antara model pengukuran (outer model) dan model struktural (inner model). Nilai GoF index ini diperoleh dari averages communalities index (AVE) dikalikan dengan $\mathrm{R}^{2}$ model. Nilai GoF ini terbentang antara $0-1$ dengan interpretasi nilai adalah 0,1 (GoF kecil), 0,25 (GoF moderat), dan 0,38 (GoF besar).

6. Uji Hipotesis (Resampling Bootstraping)

Berdasarkan tujuan-tujuan penelitian, maka rancangan uji hipotesis yang dapat dibuat merupakan rancangan uji hipotesis dalam penelitian ini disajikan berdasarkan tujuan penelitian. Tingkat kepercayaan yang digunakan adalah 95\%, sehingga tingkat presisi atau batas ketidakakuratan sebesar $(\alpha)=5 \%=0,05$. Dan menghasilkan nilai t-tabel sebesar 1,96 .

Sehingga:

- Jika nilai t-hitung lebih kecil dari nilai t-tabel [t-hitung < 1.96], maka H0 diterima dan Ha ditolak.

- Jika nilai t-hitung lebih besar dari nilai t-tabel [t-hitung > 1.96], maka H0 ditolak dan Ha diterima.

\section{HASIL}

\section{Evaluasi Model Pengukuran (Uji Validitas dan Reliabilitas)}

Evaluasi ini meliputi dua tahap, yaitu evaluasi terhadap convergent validity dan discriminant validity.

a. Evaluasi Convergent Validity 


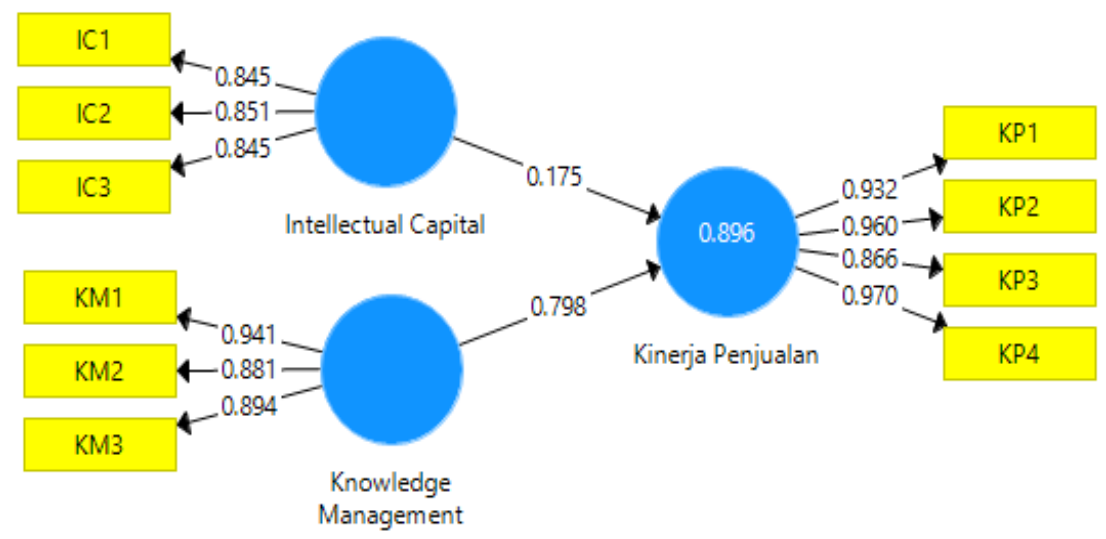

Gambar 3. PLS Algorithm Output

Bila nilai loading factor $>0,70$. Sedangkan bila nilai loading factor $\leq 0,70$; maka indikator tersebut dikeluarkan dari model.

Berikut adalah evaluasi model pengukuran terhadap validitas indikator.

Berdasarkan Gambar 3 dan Tabel 2, semua indikator memiliki nilai loading factor > 0,70 ; maka semua indikator dinyatakan valid.

Tabel 2. Nilai Loading Factor Indikator

\begin{tabular}{|l|c|l|c|}
\hline \multicolumn{1}{|c|}{ Indikator } & $\begin{array}{c}\text { Nilai } \\
\text { Loading } \\
\text { Factor }\end{array}$ & \multicolumn{1}{|c|}{ Indikator } & $\begin{array}{c}\text { Nilai } \\
\text { Loading } \\
\text { Factor }\end{array}$ \\
\hline IC1 <- Intellectual Capital & 0,845 & KM3 <- Knowledge Management & 0,894 \\
\hline IC2 <- Intellectual Capital & 0,851 & KP1 <- Kinerja Penjualan & 0,932 \\
\hline IC3 <- Intellectual Capital & 0,845 & KP2 <- Kinerja Penjualan & 0,866 \\
\hline KM1 <- Knowledge Management & 0,941 & KP3 <- Kinerja Penjualan & 0,933 \\
\hline KM2 <- Knowledge Management & 0,881 & KP4 <- Kinerja Penjualan & 0,970 \\
\hline
\end{tabular}

Sumber: Data primer diolah (2019)

Evaluasi selanjutnya dari convergent validity adalah reliabilitas konstruk dengan melihat nilai composite reliability dan nilai cronbach's alpha. Bila nilai composite reliability > 0,70 dan nilai cronbach's alpha $>0,50$; maka konstruk dinyatakan reliabel.

Tabel 3. Nilai Composite Reliability dan Cronbach's Alpha

\begin{tabular}{|l|c|c|}
\hline \multicolumn{1}{|c|}{ Konstruk } & Composite Reliability & Cronbach's Alpha \\
\hline Intellectual Capital & 0,884 & 0,819 \\
\hline Knowledge Management & 0,932 & 0,890 \\
\hline Kinerja Penjualan & 0,964 & 0,950 \\
\hline
\end{tabular}

Sumber: Data primer diolah (2019)

Berdasarkan Tabel 3, semua konstruk memiliki nilai composite reliability $>0,70$ dan nilai cronbach's alpha $>0,50$; maka dapat dinyatakan semua konstruk reliabel.

Evaluasi terakhir dari convergent validity adalah melihat nilai average variance extracted (AVE).

Tabel 4. Nilai Average Variance Extracted (AVE)

\begin{tabular}{|l|l|}
\hline Konstruk & AVE \\
\hline Intellectual Capital & 0,717 \\
\hline Knowledge Management & 0,820 \\
\hline
\end{tabular}




\begin{tabular}{|l|l|}
\hline Kinerja Penjualan & 0,871 \\
\hline Sumber: Data primer diolah (2019)
\end{tabular}

Berdasarkan Tabel 4, semua nilai average variance extracted (AVE) konstruk > 0,50; maka dapat disimpulkan semua konstruk memiliki convergent validity yang baik.

b. Evaluasi Discriminant Validity

Evaluasi discriminant validity dilakukan dengan melihat nilai cross loadings. Kriteria dalam cross loadings adalah bahwa setiap indikator yang mengukur konstruknya haruslah berkorelasi lebih tinggi dengan konstruknya dibandingkan dengan konstruk lainnya. Hasil keluaran cross loadings adalah sebagai berikut.

Berdasarkan Tabel 5, semua indikator memiliki discriminant validity yang baik, karena berkorelasi lebih tinggi dengan konstruknya masing-masing dibandingkan dengan konstruk lainnya.

Tabel 5. Nilai Cross Loadings

\begin{tabular}{|c|c|c|c|}
\hline & $\begin{array}{c}\text { Intellectual } \\
\text { Capital }\end{array}$ & $\begin{array}{c}\text { Knowledge } \\
\text { Management }\end{array}$ & $\begin{array}{c}\text { Kinerja } \\
\text { Penjualan }\end{array}$ \\
\hline IC1 & $\mathbf{0 , 8 4 5}$ & 0,568 & 0,500 \\
\hline IC2 & $\mathbf{0 , 8 5 1}$ & 0,611 & 0,537 \\
\hline IC3 & $\mathbf{0 , 8 4 5}$ & 0,805 & 0,906 \\
\hline KM1 & 0,779 & $\mathbf{0 , 9 4 1}$ & 0,936 \\
\hline KM2 & 0,720 & $\mathbf{0 , 8 8 1}$ & 0,749 \\
\hline KM3 & 0,716 & $\mathbf{0 , 8 9 4}$ & 0,855 \\
\hline KP1 & 0,775 & 0,906 & $\mathbf{0 , 9 3 2}$ \\
\hline KP2 & 0,796 & 0,864 & $\mathbf{0 , 9 6 0}$ \\
\hline KP3 & 0,704 & 0,825 & $\mathbf{0 , 8 6 6}$ \\
\hline KP4 & 0,806 & 0,904 & $\mathbf{0 , 9 7 0}$ \\
\hline
\end{tabular}

Sumber: Data primer diolah (2019)

\section{Evaluasi Goodness of Fit (GoF)}

Untuk mengevaluasi GoF dalam penelitian ini, maka diperlukan nilai akhir $\mathrm{R}^{2}$ dari tabel $R$ Square.

Tabel 5. Nilai $R$ Square

\begin{tabular}{|l|c|}
\hline Konstruk & $\boldsymbol{R}$-Square $\left(\mathbf{R}^{\mathbf{2}}\right)$ \\
\hline Kinerja Penjualan & 0,896 \\
\hline
\end{tabular}

Sumber: Data primer diolah (2019)

Nilai $\mathrm{R}^{2}$ konstruk kinerja penjualan adalah 0,896 artinya konstruk knowledge management dan intellectual capital mampu menjelaskan peningkatan kinerja penjualan sebesar $89,6 \%$, sisanya sebesar $10,4 \%$ yang tidak diteliti di dalam penelitian ini.

Setelah dilakukan pengolahan data di atas, maka dapat melakukan validasi mode secara keseluruhan, yang dilihat dari Goodness of Fit (GoF) yang formulanya adalah sebagai berikut.

$$
\begin{gathered}
\text { GoF }=\sqrt{\overline{C o m \times R^{2}}} \\
\text { Com }=A V E
\end{gathered}
$$

GoF konstruk kinerja penjualan adalah:

$$
\text { GoF }=\sqrt{0,871 \times 0,896}=0,780
$$


Nilai GoF terbentang antara 0 sd 1 dengan interpretasi nilai-nilai: 0,1 (GoF kecil), 0,25 (GoF moderat), dan 0,36 (GoF besar). Nilai GoF yang didapat 0,780 Maka dapat disimpulkan, secara keseluruhan model struktur adalah fit.

\section{Evaluasi Model Struktural (Uji Hipotesis)}

Langkah pertama yang dilakukan adalah melihat korelasi antara konstruk berdasarkan hasil Latent Variable Correlations berikut ini.

Tabel 6. Nilai Korelasi antar Konstruk

\begin{tabular}{|l|c|}
\hline Korelasi antar Konstruk & r \\
\hline Intellectual Capital dengan Kinerja Penjualan & 0,826 \\
\hline Knowledge Management dengan Kinerja Penjualan & 0,941 \\
\hline
\end{tabular}

Sumber: Data primer diolah (2019)

Untuk melihat signifikansi hubungan jalur antar konstruk, maka dilihat nilai t-hitung jalur seperti pada Gambar 4.

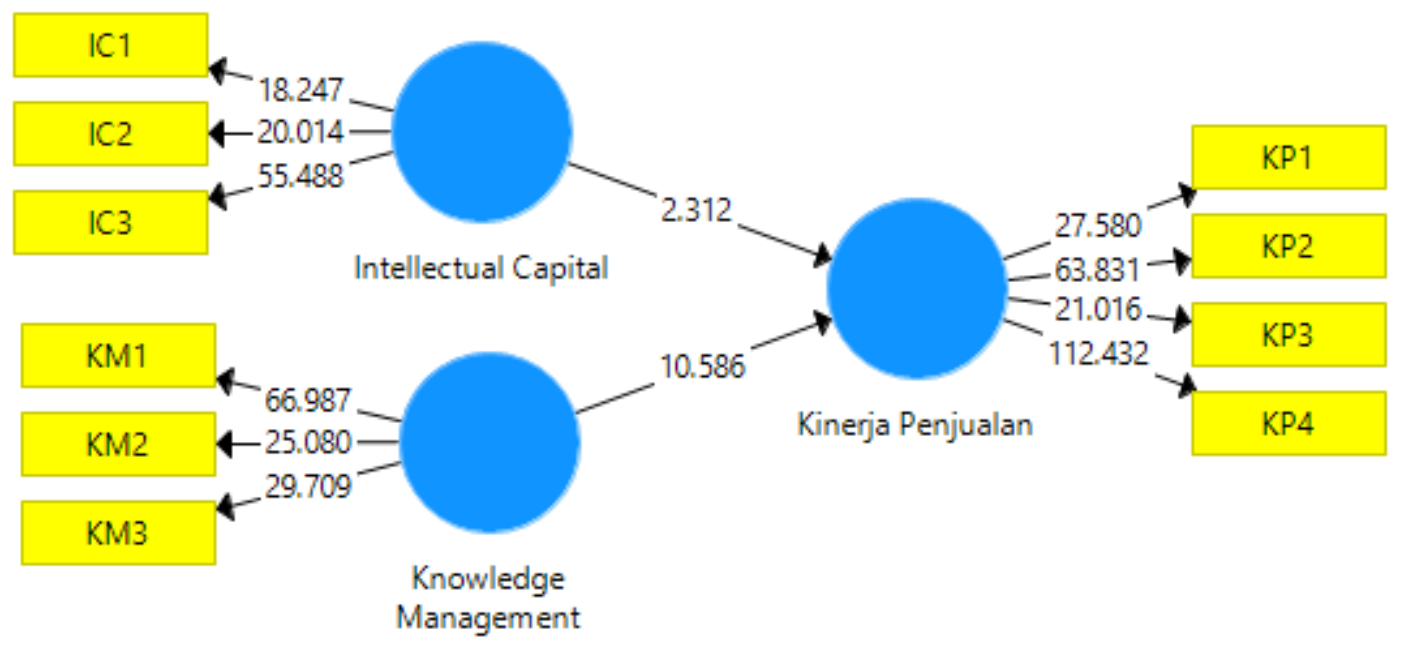

Gambar 4. Nilai CR Hubungan Jalur

Berdasarkan Gambar 4 dan Tabel 6, untuk melihat hubungan jalur bersifat signifikan, yaitu dengan membandingkan dengan $\mathrm{t}$ hitung dengan $\mathrm{t}$ tabel, signifikan jika $\mathrm{t}$ hitung $>\mathrm{t}$ tabel; $\mathrm{t}$ tabel $\alpha 0,05=1,96$.

Tabel 6. Hubungan Jalur antar Konstruk

\begin{tabular}{|l|c|c|c|c|}
\hline Direct Effect & $\begin{array}{c}\text { Path } \\
\text { Coefficients }\end{array}$ & CR & $\begin{array}{c}\text { P } \\
\text { Value }\end{array}$ & Keterangan \\
\hline Intellectual Capital -> Kinerja Penjualan & 0,175 & 2,312 & 0,021 & Signifikan \\
\hline Knowledge Management -> Kinerja Penjualan & 0,794 & 10,586 & 0,000 & Signifikan \\
\hline
\end{tabular}

Sumber: Data primer diolah (2019)

\section{PEMBAHASAN}

\section{Pengaruh Intellectual Capital Dan Knowledge Management Terhadap Peningkatan Kinerja Penjualan}

Terdapat pengaruh positif dan siginifikant antara intellectual capital dan knowledge management terhadap peningkatan kinerja penjualan (t hitung $>1,960$ ). Dengan demikian intellectual capital berpengaruh positif dan signifikan terhadap peningkatan kinerja penjualan 
dengan path coefficients sebesar 0,175 dan knowledge management berpengaruh positif dan signifikan dengan path coefficients sebesar 0,794, dengan demikian semakin tinggi intellectual capital dan knowledge management maka akan semakin tinggi peningkatan kinerja penjualan. Hal ini dapat dilihat dari nilai determinasi yaitu sebesar 0,896 yang menunjukkan peningkatan kinerja penjualan dapat dijelaska oleh intellectual capital dan knowledge management sebesar 89,6\% dan sisanya sebesar 10,4\% dijelaskan oleh variabel lain yang tidak diteliti dalam penelitian in.

Hermawan (2015) menyatakan bahwa integrasi IC dan KM dapat mempengaruhi kinerja bisnis perusahaan. Interaksi antar komponen IC (human capital, Structural capital, relational capital) terbukti saling berpengaruh. Demikian pula dengan interaksi antara KM eneblers dan KM creasen process. Akhirnya interaksi antara IC dan KM dengan kinerja bisnis terbukti berpengaruh. Hal ini memberikan bukti bahwa IC dan KM dapat diintegrasikan untuk peningkatan kinerja bisnis perusahaan farmasi di Jawa Timur. Beberapa hasil penelitian yang menyatakan bahwa intellectual capital merupakan hal krusial dan berpengaruh terhadap kinerja bisnis, kinerja penjualan, nilai tambah perusahaan, efektifitas organisasi, daya saing, dan menciptakan kesejahteraan (IFAC 1998; Bontis 1998; Belkaoui 2003; Mageza 2004; Chen et al. 2004; Cabrita et al. 2007; Sharabati et al. 2010; Indriastuti \& Arifah, 2012; Khalique et al. 2011 dalam Hermawan, 2015; Indriastuti \& Arifah, 2012; Dristianto \& Rodhiyah, 2016; Zuliyati \& Delima, 2017; Humairoh \& Agung, 2019). Jika perusahaan mampu mengkodefikasi pengetahuan dan mengembangkan IC maka keunggulan bersaing dapat dicapai. Keunggulan tersebut secara relatif akan menghasilkan kinerja penjualan UKM yang lebih tinggi. Kinerja UKM merupakan tingkat keberhasilan yang dicapai baik secara kualitas maupun kuantitas dari tingkat capaian yang telah ditargetkan. Pada saat ini UKM dituntut untuk mengoptimalkan modal intelektual (pengembangan berbasis pengetahuan) yang dimilikinya, sehingga UKM diharapkan dapat fokus pada upaya untuk mengelola melalui modal intelektual.

UKM dapat belajar bagaimana menggunakan kombinasi dari unsur manusia, struktural dan modal relasional yang mereka miliki untuk meningkatkan kapasitas mereka sendiri untuk bersaing di dunia pasar global (Mertins dan Will, 2007 dalam Dristianto \& Rodhiyah, 2016). Hal yang perlu dilakukan UKM, misalnya untuk mengembangkan modal manusia yang dimilikinya adalah dengan mengadakan pelatihan dan pendidikan para karyawannya secara berkesinambungan (Humairoh \& Agung, 2019). Modal intelektual tidak hanya mencakup hak paten, hak cipta, dan bentuk-bentuk lain dari kekayaan intelektual, namun merupakan sinergi pengetahuan perusahaan, pengalaman, hubungan, proses, penemuan, inovasi, keberadaan pasar dan pengaruh masyarakat.

Demikian juga dengan pengaruh knowledge management $(\mathrm{KM})$ terhadap kinerja bisnis dan efektifitas organisasi (Choi 2002; Kasim 2008). Choi 2002; Kasim 2008; Hsiao et al., 2011; Devie \& Kusuma, 2013; Rofiaty, et al. 2015; Saraswati \& Widiartanto, 2016 mengemukakan bahwa semua indikator pada knowledge management memberikan kontribusi yang cukup baik dalam mempengaruhi kinerja penjualan. Pelaku usaha UKM memandang bahwa knowledge managament suatu yang perlu dikembangkan untuk menyesuaikan dengan perubahan kemajuan lingkungan/pasar baik secara internal maupun eksternal. Knowledge management telah menjadi salah satu faktor penentu keberhasilan peningkatan kinerja penjualan. Kinerja penjualan dan kemampuan untuk bertahan dalam persaingan ditentukan oleh kecepatan sebuah perusahaan dalam mengembangkan kompetensi berbasis pengetahuan. Dengan pengetahuan sebuah perusahaan dapat tetap mempertahankan keunggulan bersaingnya dengan membangun kapabilitas untuk belajar lebih cepat dari pesaingnya di pasar global.

Hal ini menandakan bahwa memang keduanya (IC dan KM) memiliki peran penting dalam berbagai aktivitas di perusahaan baik aktivitas strategis maupun operasional. Namun 
peran penting IC dan KM ini belum banyak diketahui, diidentifikasikan, bahkan belum dimanfaatkan dengan baik. IC dan KM perlu diintegrasikan karena keduanya terbukti mampu untuk meningkatkan nilai tambah bagi perusahaan (Zhou dan Fink 2003) dan meningkatkan efektifitas organisasi (Hsu 2006)

\section{KESIMPULAN DAN IMPLIKASI KEBIJAKAN}

\section{Kesimpulan}

Hasil penelitian terhadap peningkatan kinerja penjualan UKM menunjukkan bahwa kedua variabel laten eksogen yaitu intellectual capital dan knowledge management mempunyai pengaruh positif dan signifikan terhadap peningkatan kinerja penjualan UKM.

\section{Implikasi Kebijakan}

Berdasarkan kesimpulan dan pembahasan yang diperoleh dari hasil penelitian, maka peneliti mencoba memberikan masukan yang dapat dijadikan bahan referensi bagi pelaku usaha dan instansi/dinas terkait dengan usaha UKM. Beberapa masukan yang hendak peneliti sampaikan adalah sebagai berikut:

1. Pelaku usaha UKM perlu terus meningkatkan pengetahuan dan ketrampilan sesuai dengan jenis usahanya, hal tersebut dapat diperoleh melalui keikutsertaanya dalam pelatihan yang diselenggarakan oleh Pemda Kota Tangerang melalui dinas-dinas terkait atau instansi lain.

2. Pelaku usaha UKM harus mulai peduli terhadap pengelolaan pengetahuan (knowledge management) dan modal intelektual (intellectual capital) pada usahanya karena hal itu dapat menumbuhkan penciptaan ide-ide inovasi baru dalam menghasilkan produk-produk baru sehingga dapat meningkatkan penjualan usahanya melalui relasi/mitra usaha atau media sosial.

\section{REFERENSI}

Choi, Byounggu, Simon K. Poon \& Joseph G. Davis. (2008). "Effects of Knowledge Management Stra-tegy on Organizational Performance: A Com-plementarity TheoryBased Approach", The International Journal of management Science, page: 235-251

Dristianto \& Rodhiyah. (2016). Pengaruh Intellectual Capital Terhadap Kinerja Penjualan Melalui Inovasi Produk Sebagai Variabel Intervening Pada Usaha Kecil Dan Menengah Batik Tulis Lasem Kabupaten Rembang. Administrasi Bisnis, Fakultas Ilmu Sosial dan Ilmu Politik, Universitas Diponegoro. Jurnal Ilmu Administrasi Bisnis, 2016

Ferdinand. (2006). Metode Penelitian Manajemen. Semarang: Badan. Penerbit Universitas Diponegoro

Hermawan, S., et al. (2015). Integrasi Intellectual Capital dan Knowledge Management Serta Dampaknya Pada Kinerja Bisnis Perusahaan Farmasi. Universitas Muhammadiyah Sidoarjo (UMSIDA) Jl. Raya Gelam No. 250 Candi Sidoarjo, Jawa Timur, Jurnal Akuntansi Multiparadigma, Volume 6, Nomor 3, Desember 2015, Hlm. 385-39

Hudgins M.R. (2014). The Impact of Intellectual Capital on the Performance of US PropertiCasualty Insurance Company. Business and Economic Journal. Vol 5 : 120

Humairoh \& Agung Budi. (2019). Peningkatan Penjualan UKM Berbasis Intellectual Capital dan Inovasi Produk. Procceding pada Seminar Nasional Kajian Multidisiplin 
Ilmu dalam Pengembangan Potensi daerah di Era Revolusi Industri 4,0. LP3M, UMT. Hotel Golden Tulip 5 agustus 2019.

Hsu, H.Y. Sonya F. (2006). Knowledge Management and Intellectual Capital. Unpublished Dissertation. Carbondale, Southern Illinois University. USA.

Indriastuti \& Arifah. (2012). Peningkatan Kerja UKM Dengan Pengelolaan Intellectuan Dan Inovasi. Conference in Business, Accounting dan Management Vol. 1 No. 1 Desember 2012 hlm 649-699

Kasim, R.S.R.. 2008. The Relationship of Knowledge Management Practices, Competencies and Organizational Performance of Government Departments in Malaysia. World Academy of Science, Engineering and Technology, hlm 53 - 59

Rofiaty, et al. (2015) Pengaruh Knowledge Management Te rhadap Inovasi, Implementasi Strategi dan Kinerja Organisasi (Studi Pada RS Lavalette Malang). Fakultas Ekonomi dan Bisnis Universitas Brawijaya Malang Fakultas Matematika dan Ilmu Pengetahuan Alam Universitas Brawijaya. Jurnal Ekonomi Bisnis Tahun 20, Nomor 1, Maret 2015, hlm 1-52

Saraswati, A \& Widiartanto, M.AB. (2016). Pengaruh Implementasi Knowledge Management Terhadap Kinerja Organisasi Melalui Inovasi Sebagai Variabel Intervening (Studi Kasus Pada UMKM Industri Kreatif Digital di Kota Semarang). Jurusan Ilmu Administrasi Bisnis Fakultas Ilmu Sosial dan Ilmu Politik Universitas Diponegoro.

Sugiyono. (2014). Metode Penelitian Kuantitati, Kualitatif dan $R \& D$. alfabeta, Badung

Zuliyati \& Z.M. Delima. (2017) Intellectual Capital Dan Kinerja UMKM. Seminar Nasional dan Call for Paper 2017. Strategi Pengembangan Sumber Daya Manusia Melalui Publikasi Jurnal Ilmiah dalam Menyikapi Permenristekdikti RI No.20 Tahun 2017. Hotel Grasia, 9 Mei 2017. Pascasarjana (S2) STIE Dharmaputra Semarang

Zhou, A.Z., dan D. Fink. (2003). "Knowledge Management and Intellectual Capital : An Empirical Examination of Current Practice in Australia." Knowledge Management Research \& Practices, Vol. 1, hlm 86-94. 